\title{
Severe upper gastrointestinal polyposis associated with sparse colonic polyposis in a familial adenomatous polyposis family with an APC mutation at codon 1520
}

\author{
B A Leggett, J P Young, K Biden, R L Buttenshaw, N Knight, A E Cowen
}

\begin{abstract}
Background-Familial adenomatous polyposis usually results in colonic polyposis with hundreds to thousands of polyps, congenital hypertrophy of the retinal pigment epithelium (CHRPE), and variable extracolonic features. Recent reports indicate that patients with distal mutations between codons 1445 and 1578 do not express CHRPE and have a high incidence of desmoid tumours.

Patients-The family studied has an unusual phenotype of sparse colonic polyposis but profuse upper gastrointestinal polyposis. Affected subjects do not have CHRPE. Methods-The protein truncation test followed by sequencing identified a 2 base pair deletion at codon 1520 in the APC gene. This results in a frameshift creating a stop codon 13 codons downstream.

Results-This family demonstrates that sparse colonic polyposis but severe upper tract polyposis may be associated with mutations between codons 1445 and 1578 . Conclusions-Study of duodenal and colonic polyps in further cases with mutations in this region is warranted. Such mutations may preferentially cause duodenal adenomas and desmoid tumours as somatic mutations in these tumours also occur in this region, unlike colorectal tumours where somatic mutations occur more proximally. This study emphasises the importance of screening the upper gastrointestinal tract even when the colonic disease is mild. (Gut 1997; 41: 518-521)
\end{abstract}

Keywords: familial adenomatous polyposis; duodenal polyps; APC mutations; colorectal polyps

Familial adenomatous polyposis (FAP) is an inherited disorder in which hundreds to thousands of adenomatous polyps develop in the colon. Cancer is virtually inevitable unless colectomy is performed. Most individuals later develop upper gastrointestinal polyps but these often remain small and the risk of malignancy is less than in the colon. ${ }^{12}$ Many affected individuals have retinal lesions known as congenital hypertrophy of the retinal pigment epithelium (CHRPE). ${ }^{3}$

FAP is due to mutation in the APC gene. Over 300 different germline mutations have been described scattered throughout the $5^{\prime}$ (proximal) half of the gene. ${ }^{4}$ Mutations near codon 1309 are associated with profuse polyposis (>2000 polyps)..$^{5-7}$ Mutations in the extreme proximal region of the gene are associated with attenuated disease with fewer than 100 polyps. $^{8}$

Relatively few families have mutations 3' (distal) to codon 1444. Recent studies report that these individuals do not express CHRPE and have a high incidence of desmoid tumours. $^{910}$ The severity of polyposis in the upper gastrointestinal tract and colon was not reported. Other studies report mutations 3' of codon 1403 resulting in unpredictable and often severe phenotypes with extracolonic features. ${ }^{11}{ }^{12}$ In the present study, we report a family with an APC mutation in this region and an unusual phenotype.

\section{Methods}

PATIENTS

The family was referred to the Queensland FAP Register and included in the genetic testing programme. All members of the family gave written informed consent. Affected members underwent colonoscopy and upper endoscopy as clinically indicated.

\section{LABORATORY DATA}

DNA was extracted from blood by a modified salt precipitation technique. ${ }^{13}$ The APC gene was screened for mutations using the protein truncation test essentially according to van der Luit et $a l^{14}$ and heteroduplex/single stranded conformation polymorphism assays according to the manufacturer's recommendations (MDE Gel Solution, AT Biochem, USA). A polymerase chain reaction fragment of exons 15-7 was cloned into T-vectors ${ }^{15}$ and sequenced on an ABI Automated Sequencer.

\section{Results}

Figure 1 shows the pedigree. The proband (I:1) was 29 years old when she presented with rectal bleeding. Colonoscopy showed 33 polyps which were removed and histologically confirmed to be adenomas. There was no known family history of polyps or colorectal cancer. Over the next seven years, 157 polyps were removed. At age 37 she was commenced on sulindac and over the past 10 years has had only 20 colorectal polyps removed in total during annual colonoscopic examinations. Indirect ophthalmoscopy for CHRPE was negative. A
Accepted for publication 2 May 1997 

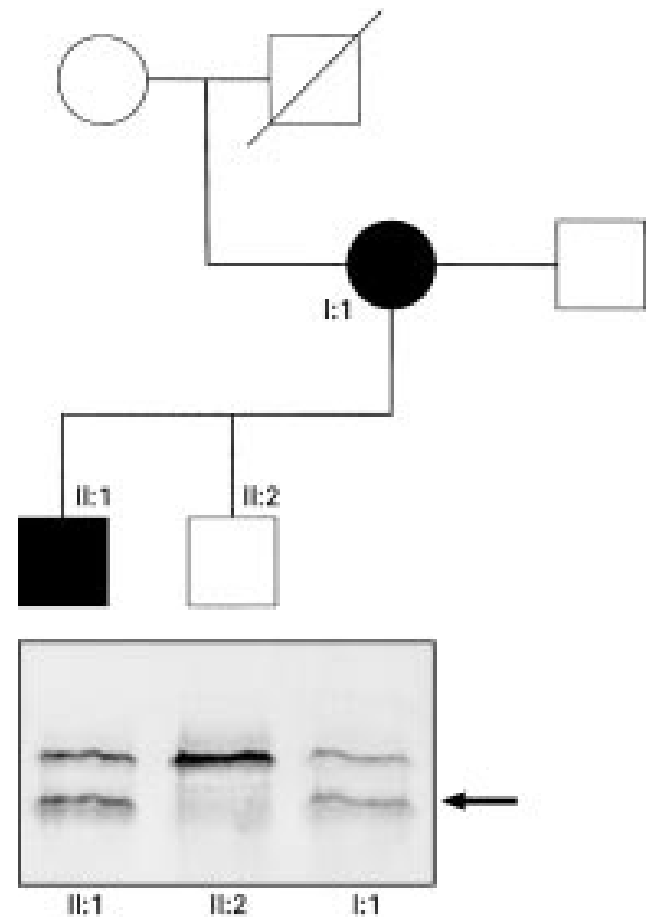

Figure 1: Pedigree of the family. Circles represent females, squares males. Filled symbols represent individuals known to be affected. In the lower half of the figure are the results of the protein truncation test. An additional truncated protein product (arrowed) is present in samples from affected individuals following in vitro transcription/ translation of exon 15 segment 3.

histologically confirmed fibroma was removed from the axilla at age 44 but examination reveals no other features of Gardner's syndrome.

At age 38, upper endoscopy was performed because of dyspepsia. It showed a $3 \mathrm{~cm}$ sessile polyp of the pyloric canal which was removed endoscopically and histologically confirmed to be an adenoma. In addition there were multiple small polyps throughout the stomach and approximately 40 polyps in the first and second parts of the duodenum including a sessile villous adenoma occupying most of the first part. These lesions were subjected to extensive diathermy on multiple occasions. A radiological small bowel study showed no polyps in the remaining small intestine. At age 40 partial gastrectomy of the distal stomach was performed. Histology confirmed a $2.5 \mathrm{~cm}$ sessile

APC gene

Germline mutations

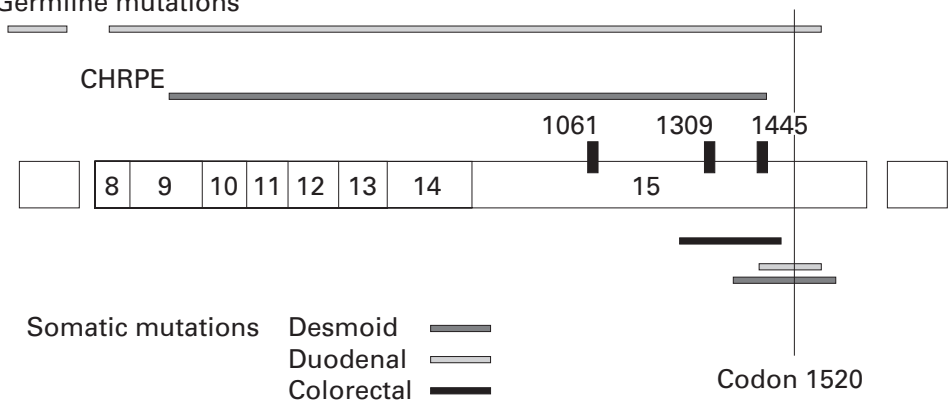

Figure 2: Schematic diagram of the central portion of the APC gene showing the region in which germline mutations known to cause FAP occur. Exons are labelled 8 to 15. tubulovillous adenoma of the pylorus and multiple fundic gland polyps. Moderate dysplasia was present in the large adenoma. At this time the patient had stage IV duodenal polyposis according to the Spigelman criteria. ${ }^{16}$ Despite continuing regular extensive diathermy of duodenal polyps she required a duodenotomy at age 45 to remove a very large sessile adenoma. Histology showed a specimen measuring $70 \times 45 \times 20 \mathrm{~mm}$ consisting entirely of tubulovillous adenoma with severe dysplasia. Her polyposis is considered particularly severe as both her stomach and duodenum are carpeted with polyps such that virtually no normal mucosa remains.

The proband's two sons were screened. Individual II:2 (fig 1) had normal flexible sigmoidoscopies at ages 18 and 20 and a normal upper endoscopy at age 20. Genetic testing has shown that he does not carry the mutated APC gene. Individual II: 1 had six colonic polyps removed at age 16 and was started on sulindac. Subsequent colonoscopy at age 18 was normal. Upper endosocpy at age 18 showed six duodenal adenomas and fundic gland polyps in the stomach. Upper endoscopy at age 21 showed more than 20 duodenal polyps, the largest of which was $5 \mathrm{~mm}$ in size. Histology showed tubular adenomas with mild dysplasia (Spigelman stage III). Colonoscopy at age 21 , while not on sulindac, showed scattered polyps from caecum to rectum with less than 100 in total. Genetic testing shows him to have inherited the mutant APC gene. Examination for CHRPE was negative.

Protein truncation testing showed a truncated protein produced from exon 15 segment 3 (fig 1 ) in the proband (I:1) and individual II:1. These subjects showed positive heteroduplex bands in fragment 15-7. Sequencing of this fragment showed a 2 base pair deletion at codon 1520 thus changing the sequence from ...GAT GTG GAA... to ...GGT GGA A... This deletion causes a frameshift mutation which results in a stop codon 13 codons downstream. Figure 2 shows the location of this mutation within the APC gene. The locations of codons 1061 and 1309 which are hotspots for germline mutations are shown. Germline mutations after codon 1445 are associated with a high incidence of desmoid tumours. ${ }^{9}$ The region in which germline mutations are associated with CHRPE is shown. ${ }^{9}{ }^{18}$ The lower portion of the figure shows the regions in which somatic mutations in tumours from FAP patients preferentially occur. ${ }^{17} 1920$ The mutation in the family reported is at codon 1520 which is beyond the region of frequent mutation in colorectal tumours but within the regions mutated in duodenal and desmoid tumours. Mutations at or close to codon 1520 may selectively promote duodenal and desmoid tumorigenesis rather than profuse colonic polyposis.

\section{Discussion}

This family has an unusual phenotype with sparse colonic polyposis but severe polyposis of the stomach and duodenum. The mutation falls within the region between codons 1445 
and 1578 recently described by Caspari et al and Davies et al. ${ }^{10}$ In their studies only $8 \%$ and $15 \%$ respectively of mutations were found in this region; this is the only such mutation we have found in 18 unrelated families in whom APC mutations have been identified. This family corresponds to the phenotype described in that affected individuals do not express CHRPE.

Neither of these studies report the numbers of colonic polyps found in subjects with mutations in this region. Nagase et $a l^{\bar{l}}$ defined profuse polyposis as $>5000$ polyps and found it to be associated with mutations between codons 1250 and 1330. Mutations 5' (proximal) to this caused sparse polyposis and the three cases with 3' (distal) mutations at codons 1464 (two separate mutations) and 1597 had sparse polyposis. Subsequent studies confirmed these findings ${ }^{6717}$ although in Western studies the total polyp count is lower; $>2000$ polyps usually represents profuse polyposis and $<500$ sparse polyposis. Our proband undoubtedly fits the sparse phenotype having had only 33 polyps at presentation at the age of 29 . A recent study by Dobbie et $a l^{11}$ reported six families with a mutation 3' of codon 1403 who had unpredictable and often severe phenotypes including "stomach polyps". Scott et $a l^{12}$ also reported a family with a 3 ' mutation and a variable phenotype. These reports suggest that $3^{\prime}$ mutations may be associated with different phenotypes to those observed with more common mutations and are worthy of further study.

Somatic mutations occurring in colorectal neoplasms both in the sporadic and FAP settings are more closely clustered between codons 1280 and 1500 than the germline mutations causing FAP (fig 2). ${ }^{18}$ Both mutations downstream of codon 1445 and mutations upstream of exon 9 are associated with sparse polyposis and lack of $\mathrm{CHRPE}^{19}$ which suggests that the malfunction of the APC protein which most efficiently causes colonic polyposis also causes CHRPE.

An earlier study did not show upper gastrointestinal polyps to be more common with any particular mutation but no patients with mutations between codons 1445 and 1578 were examined. ${ }^{17}$ Our family suggests that mutations in this region may result in very severe upper tract polyposis. Furthermore, somatic APC mutations in duodenal tumours preferentially occur between codons 1450 and $1556^{20}$ and in desmoid tumours between codons 1399 and $1581^{21}$ (fig 2). These correlations suggest that subtle differences in the function of mutant APC proteins may selectively promote tumorigenesis in different cell types.

An alternative explanation for the unusual phenotype observed in our family would be that a modifying gene is cosegregating with the disease. A modifier gene affects the expression of the mouse equivalent of FAP and an excellent candidate for this modifier gene is secretory phospholipase $\mathrm{A}_{2} \cdot{ }^{22}{ }^{23}$ One difficulty in postulating that a modifier gene is the cause of the unusual phenotype in our family is that such a gene would need to reduce colonic polyposis while increasing duodenal polyposis. Secretory phospholipase $\mathrm{A}_{2}$ is thought to act by increasing arachidonic acid production and thus cell signalling via prostaglandins and leukotrienes to reduce polyp formation. To explain the phenotype in the present family, it would need to have widely differing activities in the colon and duodenum.

In summary, we have described a family with FAP due to a mutation in APC codon 1520 who have sparse colonic polyposis but severe upper gastrointestinal polyposis. The small number of cases in this family limits interpretation of the data and further cases need to be studied to determine whether this unusual phenotype is due to the location of the mutation or a modifier gene which has differing effects in the duodenum and the colon. From a practical point of view this family demonstrates the need for upper tract surveillance even in FAP individuals with mild colonic disease.

This study was supported by the Queensland Cancer Fund and the Department of Pathology, Royal Brisbane Hospital.

1 Jagelman DG, DeCosse JJ, Bussey HJR and The Leeds Castle Polyposis Group. Upper gastrointestinal cancer in familial adenomatous polyposis. Lancet 1988; i: 1149-51.

2 Rhodes M, Bradburn DM. Overview of screening and management of familial adenomatous polyposis. Gut 1992; 33: 125-31.

3 Traboulsi EI, Krush AJ, Gardner EJ, Booker SV, Offerhaus GJA, Yardley $\mathrm{JH}$, et al. Prevalence and importance of pigmented ocular fundus lesions in Gardner's syndrome. pigmented ocular fundus lesions

4 Polakis P. Mutations in the APC gene and their implications for protein structure and function. Curr Opin Genet Develop 1995; 5: 66-71.

5 Nagase H, Miyoshi Y, Horii A, Aoki T, Ogawa M, Utsaunomiya J, et al. Correlation between the location of germ-line mutations in the APC gene and the number of colorectal polyps in familial adenomatous polyposis patients. Cancer Res 1992; 52: 4055-7.

6 Caspari R, Friedl W, Mandl M, Möslein G, Kadmon M, Knapp M, et al. Familial adenomatous polyposis: mutation 343: 629-32.

7 Gayther SA, Wells D, SenGupta SB, Chapman P, Neale K, Tsioupra K, et al. Regionally clustered APC mutations are associated with a severe phenotype and occur at a high frequency in new mutation cases of adenomatous polyposis
coli. Hum Mol Genet 1994; 3: 53-6.

8 Spirio L, Olschwang S, Groden J, Robertson M, Samowitz W, Joslyn G, et al. Alleles of the APC gene: an attenuated form of familial polyposis. Cell 1993; 75: 951-7.

9 Caspari R, Olschwang S, Friedl W, Mandl M, Boisson C, Böker T, et al. Familial adenomatous polyposis: desmoid tumours and lack of ophthalmic lesions (CHRPE) associated with APC mutations beyond codon 1444. Hum Mol Genet 1995; 4: 337-40.

10 Davies DR, Armstrong JG, Thakker N, Horner K, Guy S, Clancy $\mathrm{T}$, et al. Severe Gardner syndrome in families with mutations restricted to a specific region of the APC gene. Am 7 Hum Genet 1995; 57: 1151-8.

11 Dobbie Z, Spycher M, Mary J-L, Häner M, Guldenschuh I, Hürliman R, et al. Correlation between the development of extracolonic manifestations in FAP patients and mutations beyond codon 1403 in the APC gene. F Med Genet 1996; 33: $274-80$.

12 Scott RJ, van der Luijt R, Spycher M, Mary J-L, Müller HJ, Martinoli S, et al. Novel germline APC gene mutation in a large familial adenomatous polyposis kindred displaying large familial adenomatous polyposis kin

13 Miller SA, Dykes DD, Polesky HF. A simple salting out procedure for extracting DNA from human nucleated cells. Nucl Acid Res 1988; 16: 1215 .

14 van der Luijt R, Khan PM, Vasen $H$, van Leeuwen C, Tops $\mathrm{C}$, Roest $\mathrm{P}$, et al. Rapid detection of translation-terminating mutations at the adenomatous polyposis coli (APC) gene by direct protein truncation test. Genomics $1994 ; 20: 1-4$.

15 Miyoshi Y, Ando H, Nagase H, Nishisho I, Horii A, Miki Y, et al. Germline mutations of the APC gene in 53 familial adenomatous polyposis patients. Proc Natl Acad Sci USA 1992; 89: 4452-6.

16 Spigelman AD, Phillips RKS. The upper gastrointestinal tract. In: Phillips RKS, Spigelman AD, Thomson JPS, eds. Familial adenomatous polyposis and other polyposis syndromes. Lomilial adenomatous polyposis and other poly

17 Nugent KP, Phillips RKS, Hodgson SV, Cottrell S, Smith-Ravin J, Pack K, et al. Phenotypic expression in
familial adenomatous polyposis: partial prediction by mutation analysis. Gut 1994; 35: 1622-3. 
18 Miyaki M, Konishi M, Kikushi-Yanoshita R, Enomoto M, Igari $\mathrm{T}$, Tanaka $\mathrm{K}$, et al. Characteristics of somatic mutation of the adenomatous polyposis coli gene in colorectal tumors. Cancer Res 1994; 54: 3011-20.

19 Olschwang S, Tiret A, Laurent-Puig P, Muleris M, Parc R, Thomas G. Restriction of ocular fundus lesions to a specific subgroup of APC mutations in adenomatous polyposis coli patients. Cell 1993; 75: 959-68.

20 Toyooka M, Konishi M, Kikuchi-Yanoshita R, Iwama T, Miyaki $M$. Somatic mutations of the adenomatous polyposis coli gene in gastroduodenal tumours from patients with familial adenomatous polyposis. Cancer Res 1995; 55: $3165-70$
21 Miyaki M, Konishi M, Kikuchi-Yanoshita R, Enomoto $M$, Tanaka $\mathrm{K}$, Takahashi $\mathrm{H}$, et al. Coexistence of somatic and germ-line mutations of APC gene in desmoid tumors from patients with familial adenomatous polyposis. Cancer Res 1993; 53: 5079-82.

22 Tomlinson IP, Neale K, Talbot IC, Spigelman AD, Williams $\mathrm{CB}$, Phillips RK, et al. A modifying locus for familial adenomatous polyposis may be present on chromosome 1p35-p36. f Med Genet 1996; 33: 268-73.

23 Dobbie Z, Müller H, Scott RJ. Secretory phospholipase A2 does not appear to be associated with phenotypic variation in familial adenomatous polyposis. Hum Genet 1996; 98: 386-90. 